研究

$$
\begin{gathered}
\text { パラタングステン酸アンモニウムの熱分解におけるアンモニウムタングステン } \\
\text { ブロンズの生成条件 }
\end{gathered}
$$

山本 良治, 山田 正二

本川 惺, 志垣 憲良

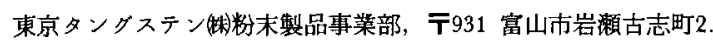

\title{
Formation Conditions of Hexagonal Ammonium Tungsten Bronze during Thermal Decomposition of Ammonium Paratungstate
}

\author{
Yoshiharu Yamamoto, Shoji Yamada \\ Satoru Honkawa and Noriyoshi Shigaki \\ Refinery \& Hardmetal Division, Tokyo Tungsten Co., Ltd., 2 Iwasekoshimachi, Toyama 931.
}

Received February 4, 1993

To define the optimum formation condition of ammonium tungsten bronze (ATB) which is very important intermediate for production of ultrafine tungsten, thermal decomposition of monoclinic and orthorhombic ammonium paratungstate (APT) was studied by thermogravimetry and differential thermal analysis in various atmospheres. The intermediate has been investigated by $X$-ray diffraction analysis and nitrogen measurement.

ATB was formed in hydrogen, in a mixture of nitrogen and ammonia, in nitrogen, in argon, in air and in oxygen atmosphere respectively. The amount of ATB formed during thermal decomposition of APT depended on the degree of proceeding of thermal decomposition near by $630 \mathrm{~K}$. In case of much sample amount, reaction rate was reduced due to the endothermic reaction related to thermal decomposition of ammonia and water in crystallization.

A small amount of ammonia was necessary for a stable formation of ATB, and the nitrogen content was above $0.8 \%$ in single-phase ATB.

\section{I 徸 言}

酸化タングステンを水素で還元してタングステン粉 末を得る際の精度は還元工程における温度，水素の露 点および流量，原料の充填量などの製造条件に侬存す るとされ，原料である酸化タングステンの粒度は注目 されていない，著者らは前報”2‘で，種々の条件下 でパラタングステン酸アンモニウム $(\mathrm{APT})$ を熱分 解して酸化タングステンの生成過程と粒度の関係を調 ベ, 六方晶アンモニウムタングステンブロンス（A T
B）を生成する過程を経て熱分解すると酸化タングス テン超微粒子が生成することを明らかにした。

A T B に関する研究は，窒菜中の鶖分解においては 生成しないとする報告 ‘’や，水素やアンモニアなどの 還元性雾囲気中で生成し，その生成条件がWへの還元 過程に影響する重要な中間生成物であるとする報告“ 5,6,7,8，'がある.しかし，A T Bの生成を支配する 因子やその因子の還元機構への影響は明らかにされて いない. 
本報では，超微粒酸化タングステンおよび超微粒タ ングステンを製造する基碬データを得るために種々の 雾囲気中における示差熱分析および熱分解生成物の X 線回折によりA P Tの熱分解におけるA T B の生成条 件を調べた。

\section{II 実的方法}

$\left(\mathrm{NH}_{4}\right)_{2} \mathrm{WO}_{4}$ 水溶波を加熱濃籍して得た単斜晶 $\mathrm{A} \mathrm{P} \mathrm{T}$ $\left(5\left(\mathrm{NH}_{4}\right)_{2} \mathrm{O} \cdot 12 \mathrm{NO}_{3} \cdot 5 \mathrm{H}_{2} \mathrm{O}\right),\left(\mathrm{NH}_{4}\right)_{2} \mathrm{WO}_{4}$ 水溶淁を室温で ゆっくりと蒸発させ結晶化して作製した斜方晶 A P T $\left(5\left(\mathrm{NH}_{4}\right)_{2} \mathrm{O} \cdot 12 \mathrm{WO}_{3} \cdot 11 \mathrm{H}_{2} \mathrm{O}\right)$ )示差熱分析およびA T B の熱分解実駼を行った。試料中の不純物をTable 1 に示す.

A P Tの示差熱分析は示差熱天秤を使用し， A P T をアルミナ製の武料容器に50-1000mgを充墳し， 0.17 $\mathrm{K} / \mathrm{s}$ の昇温速度, 453-923Kの温度範囲, 窒素, 酸 素,アルゴン, アンモニアと窒素（いづれも純度 99.999\%, 露点203 K以下) の混合(1:1)ガスおよび 空気中で行った.

A T B の熱分解はA P Tをアルミナ製の試料容器に $6000 \mathrm{mg}$ 充填し，上記の種々の票囲気中で， $0.25 \mathrm{~K} / \mathrm{s}$ の昇温速度で703Kおよび743Kまで加熱し，それそれ の温度で5.4 ks保持してATBの分解を調べた。

得られた熱分解生成物について，窒素量の定量分析 (LECO製)，X線回折(C u K $\alpha)$ によるの同定を行いA TBの生成および熱分解過程を調べた。

Table 1 Impurity contents of raw material.

\begin{tabular}{lr|c|c}
\hline & & $\begin{array}{c}\text { Monoclinic } \\
\text { APT }\end{array}$ & $\begin{array}{c}\text { Orthorhomic } \\
\text { APT }\end{array}$ \\
\hline $\mathrm{Al}, \mathrm{Sn}$ & $(\mathrm{ppm})$ & $<2$ & $<2$ \\
$\mathrm{Na}$ & $(\mathrm{ppm})$ & 5 & 6 \\
$\mathrm{Ca}, \mathrm{Cr}, \mathrm{Cu}, \mathrm{Fe},(\mathrm{ppm})$ & $<1$ & $<1$ \\
$\mathrm{Mg}, \mathrm{Mn}, \mathrm{Ni}$ & $(\mathrm{ppm})$ & $<1$ & $<1$ \\
$\mathrm{Mo}$ & $(\mathrm{ppm})$ & $<1$ & 9 \\
$\mathrm{Si}$ & $(\mathrm{ppm})$ & $<5$ & $<5$ \\
\hline
\end{tabular}

\section{III 実駺桔果むよび考察}

III-1 単斜晶 A P T の示差熱分析

Fig. 1 に単斜晶A P T の空気中での示差熱曲線, 重 量減少曲線およひ種々の温度で示差熱分析を中断して 得た熱分解生成物を示す。 Fig.2 に種々の温度での 生成物のX線回折図形および生成相の $\alpha-\mathrm{Al}_{2} \mathrm{O}_{3}$ を 内標準としたX線回折による定量分析結果を示す。

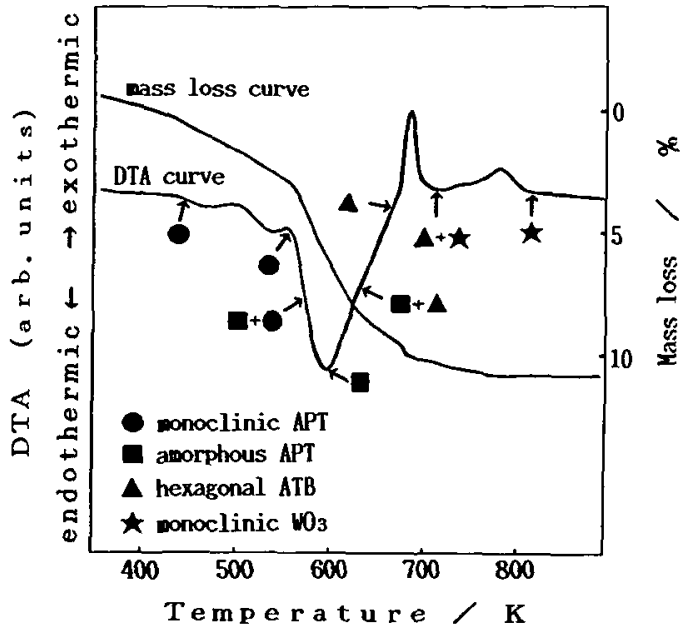

Fig.1 DTA and mass loss curves for monoclinic $A P T$, and phases of the intermediates heated to various temperatures. (sample mass : $300 \mathrm{mg}$, heating rate $: 0.17 \mathrm{~K} / \mathrm{s}$, heated in air)

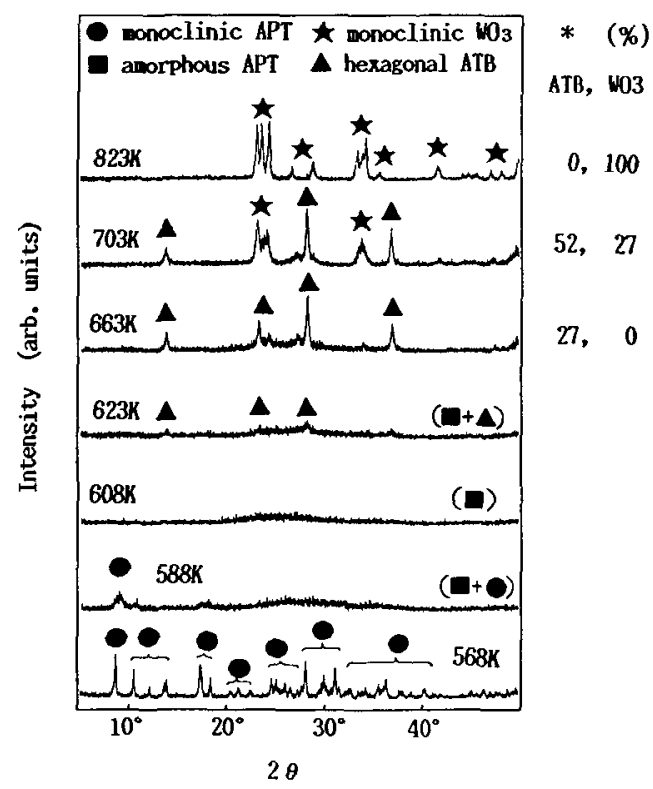

Fig. 2 X-ray diffraction patterns and quantitative analysis $(*$, internal standard method using $\left.\alpha-\mathrm{Al}_{2} \mathrm{O}_{3}\right)$ by $\mathrm{X}$-ray diffraction for decomposition intermediates of monoclinic APT heated to various temperatures. (sample mass : $300 \mathrm{mg}$, heating rate $: 0.17 \mathrm{~K} / \mathrm{s}$, heated in air)

A P Tは結晶水, アンモニアの順に解離する゙。 結晶水は $460 \mathrm{~K}$ および550K近䧛で 2 段階の小さな吸 熱を伴って解離し，この間, 単斜晶A P T のままであ る. $560 \mathrm{~K}$ 以上になると大きな吸熱を伴ったアンモ 
ニアの解離が急速に進行し, 生成物は単斜晶 A P T ら無定形 A P T へと変化する.

吸熱反応が終息に向かう630K近傍から A T B の生 成が始まり，663Kにおける生成相はA T B が27\%で 残部が無定形A P Tと考えられる. 685Kで急激に 発熱して単斜晶 $\mathrm{WO}_{3}$ 生成する。703Kにおける生 成相は A T B が52\%に增加し，無定形A P Tもまだ 21 \%ほど残っているにもかかわらず単斜晶WO 3 が27\% 生成しており，無定形 A P T から単斜晶 $\mathrm{WO}_{3}$ が生成 していると考えられる７60Kから再び紘やかな発 熟を伴ってATBは分解し単斜晶 $\mathrm{WO}_{3}$ となり, $823 \mathrm{~K}$ において生成物は単斜晶 $\mathrm{WO}_{3}$ の単相となる.

すなわち, 単斜晶A P Tは次の経路で熱分解する. 単斜晶 $\mathrm{APT} \rightarrow$ 無定形 A P T $\rightarrow$ A T B $\rightarrow$ 単斜晶 $\mathrm{WO}_{3}$

\section{III-2 A T B の生成に及ぼす単斜晶A P Tの充填量お} よび熱分解骞囲気の影響

Fig.3 に50mg，300mgおよび1000mgと A P T充填量 を変えた時の示差熱曲線を示し, Table 2に723Kまで 種々の雾囲気中で加熱した生成物を示す． A P T充 填量の增加とともに吸熱のピークが高温侧にシフトし てアンモニアの解離が遲れていることを示している。

$50 \mathrm{mg}$ および300mg の A P T充垣量の埸合, 単斜晶 $\mathrm{WO}_{3}$ の生成で発熱し, 生成物は A T B と笚斜晶 $\mathrm{WO}_{3}$ の混合物であるのに対して，1000mgの場合は723Kに おいて発熱も吸熱もなく A T B を生成する.

A P T 充埧量がA T B 生成に影響するのは次の理由

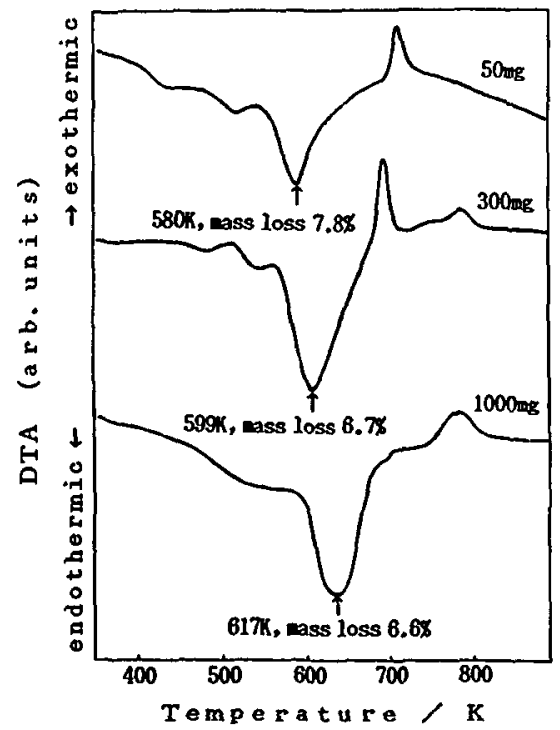

Fig. 3 Change in DTA curves with sample mass. (heated in air, heating rate : $0.17 \mathrm{~K} / \mathrm{s}$ )

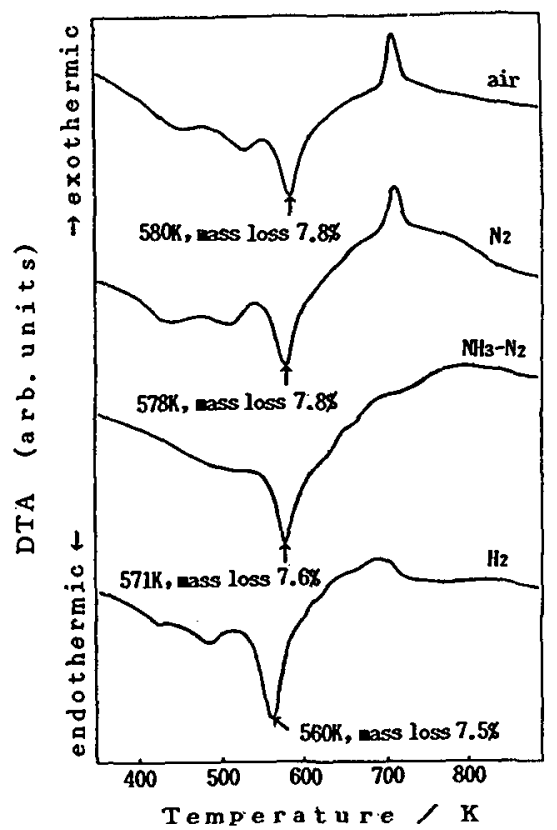

Fig.4 Change in DTA curves with thermal decomposition atmosphere.

(sample mass : $50 \mathrm{mg}$, heating rate $: 0.17 \mathrm{~K} / \mathrm{s}$ )

によると考えられる．APTの充㙋量が多いほどア ンモニアの解離による吸熱で試料の温度が下げられ， 解離反店が遅孔る。アンモニアの解離に伴う吸熱 が烽息して A T B が生成する温度域に達したとき，A T B の生成に要求される十分なアンモニアが㚜存する 時に A T B が安定に生成する.

Fig.4 に50mgのAPT充填量の種々雾团気中での示 差熱曲線を示す。空気中と犖素中では同様の示差熱 曲線を示した。

アンモニアと䇪素の混合骞囲気中では, $673 \mathrm{~K} て ゙ A$ TBを生成し，823K近傍まで単相のまま存在する。

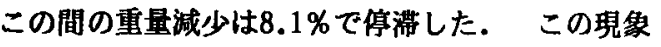
は A P T中のアンモニアと䨝囲気のアンモニアとの間 に平衡関係が成立したためと考えられる。

水素中では他の雾囲気に比較してアンモニアの解離 が速く進行し，牫存するアンモニア量が少ないため, 楥慢な発熱を伴って単斜晶 $\mathrm{WO}_{3}$ も生成して A T B の混合物になっている.

III-3 斜方晶A P Tの示差熱分析

Fig.5 に結晶水の多い科方晶 A P Tの空気中での示 差熱曲楾, 重量減少曲線, および種々の温度で示差熱 分析を中断して得た生成物を示す。

$438 \mathrm{~K}$ よび537Kに結晶水の解離に対応する吸熱の ピークが現れ，493Kから生成物の非晶質化が始まる. 


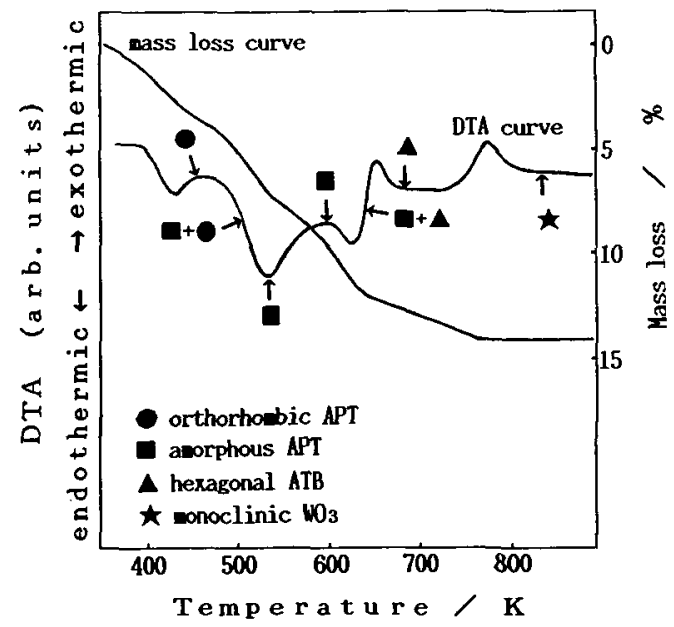

Fig.5 DTA and mass loss curves for orthorhombic APT, and phases of the intermediates heated to various temperatures. (sample mass : $300 \mathrm{mg}$, heating rate : $0.17 \mathrm{~K} / \mathrm{s}$, heated in air)

単斜晶 A P Tに比較して $430 \mathrm{~K}$ よび $540 \mathrm{~K}$ 近㜔の結 晶水の解離の吸熱が大きいのは䊅晶水が多いためと考 えられる. 636Kでアンモニアの解離が生じ; A T Bは640K近䧛から発熱を伴って生成した。 $700 \mathrm{~K} に$ おける生成物は A T B 単相である.

单斜晶 $\mathrm{APT}$ 場合は715Kで単斜晶W $\mathrm{O}_{3}$ と $\mathrm{ATB}$ の混合物であるのに対し，斜方晶 A P Tで A T B 単相 であるのは結晶水の解離による吸熱が大きいためアン モニアの分解が遅れ，A T B が単相となるための十分 なアンモニアが残存するためと考えられる。

A T B は単斜晶 A P Tの場合と同様に $760 \mathrm{~K}$ から発 熱して単斜晶 $\mathrm{WO}_{3}$ へと変化する.

III-4 A T B の生成に必要なアンモニア量

ATBの生成に必要とされるアンモニア量を明らか

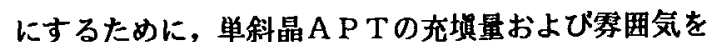
変えた示差熱分析における生成物の重量減少, 䆦素量 および生成相を調べた。

Table 2 に50-1000mgのAP T充填量で, $0.17 \mathrm{~K} / \mathrm{s}$ の加熱速度で723Kまで加熱した生成物のX線回折強 度比, 窒素量（実測值および重量減少からの計算俌） および重量減少を示す.

アンモニアと䧗素の混合ガス中では A P T 充填量に 依存せず A T Bだけで，呿素量はA P T 充填量 $1000 \mathrm{mg}$ の場合 $1.63 \%$ で $\left(\mathrm{NH}_{4}\right)_{0.28} \mathrm{BWO}_{3}$ に相当する.

酸素, 空気, 咥素, アルゴンおよび水素塞囲気中で は, 50m よおび $300 \mathrm{mg}$ の P T充填量において生成物 はA T B と单斜晶 $\mathrm{WO}_{3}$ の混合物となり, A T B の生 成量は還元性塞围気, 不活性雾囲気, 酸化性雾囲気の 順に多かった．充填量1000名では水素を除いてAT B単相を生成した。水素中では速い熱分解の進行の ために A T B 生成のためのアンモニアが残存しなかっ たことが重量減少量から明らかである。

窒素の含有量と生成物の間には強い相関がある.

窒素量 $0.83 \%\left(\left(\mathrm{NH}_{4}\right)_{0}, 13 \mathrm{WO}_{3}\right.$ に相当) 以上ではA T $\mathrm{B}$ 単相，0.8\%以下では $\mathrm{ATB}$ と単斜晶W $\mathrm{O}_{3}$ の混合物 て存在する. 実瞌值と重量減少からの算出した窒素量 を比較すると $0.8 \%$ 以上で両者は良く一致する。

少ない含有量では実測值の方が高くなるのは熱分解 が完了した単斜晶 $\mathrm{WO}_{3}$ で吸着と思われる窒素が $0.2 \%$ ほど残るためと考えられる。

\section{III-5 A T B の分解に及ぼす需囲気の影響}

$\mathrm{ATB}$ B゙単斜晶 $\mathrm{WO}_{3}$ に分解する過程を明らかにす るために，熱天科で $6000 \mathrm{mg}$ の単斜晶 $\mathrm{APT}$ T種々の筙 用気中で，0.25K/s の加熱速度で743Kまで昇温し A T B を生成させた後，それぞれの温度で5.4ks保持

Table 2 Nitrogen contents and phases of decomposition products of monoclinic APT decomposed by DTA. (heating rate : $0.17 \mathrm{~K} / \mathrm{s}$, heated to $723 \mathrm{~K}$ )

\begin{tabular}{|c|c|c|c|c|c|c|c|c|c|c|c|c|}
\hline \multirow[b]{2}{*}{ sample mass $\rightarrow$} & \multicolumn{3}{|c|}{$\begin{array}{l}\text { X-ray intensity } \\
(\text { a.u. }),\left(\mathrm{ATB} / \mathrm{WO}_{3}\right) * 1\end{array}$} & \multicolumn{3}{|c|}{$N$ content $(\mathcal{X})$} & \multicolumn{3}{|c|}{$\begin{array}{l}N \text { content }(x) \\
*^{2}\end{array}$} & \multicolumn{3}{|c|}{ Mass loss $(\not)$} \\
\hline & $50 \mathrm{mg}$ & $300 \mathrm{mg}$ & $1000 \mathrm{mg}$ & $50 \mathrm{mg}$ & $300 \mathrm{mg}$ & $1000 \mathrm{mg}$ & $50 \mathrm{mg}$ & $300 \mathrm{mg}$ & 1000 mg & $50 \mathrm{mg}$ & $300 \mathrm{mg}$ & $1000 \mathrm{mg}$ \\
\hline $\mathrm{O}_{2}$ & $36 / 100$ & $100 / 82$ & $100 / 0$ & 0.48 & 0.65 & 0.91 & 0.07 & 0.38 & 0.84 & 10.8 & 10.4 & 9.7 \\
\hline Air & $44 / 100$ & $100 / 82$ & $100 / 0$ & 0.44 & 0.69 & 0.83 & 0.07 & 0.38 & 0.78 & 10.8 & 10.4 & 9.7 \\
\hline $\mathrm{N}_{2}$ & $71 / 100$ & $100 / 97$ & $100 / 0$ & 0.49 & 0.60 & 0.99 & 0.13 & 0.38 & 0.91 & 10.7 & 10.4 & 9.6 \\
\hline $\mathrm{Ar}$ & $69 / 100$ & $98 / 100$ & $100 / 0$ & 0.46 & 0.68 & 0.90 & 0.07 & 0.42 & 0.78 & 10.8 & 10.3 & 9.8 \\
\hline $\mathrm{NH}_{3}$ and $\mathrm{N}_{2} * 3$ & $100 / 0$ & $100 / 0$ & $100 / 0$ & 1.46 & 1.56 & 1.63 & 1.90 & 1.78 & 1.78 & 7.9 & 8.1 & 8.1 \\
\hline & $100 / 91$ & $100 / 75$ & $100 / 61$ & 0.44 & 0.52 & 0.74 & 0.30 & 0.38 & 0.52 & 10.5 & 10.4 & 10.1 \\
\hline
\end{tabular}

$*^{1}$ hexagonal ATB / monoclinic $\mathrm{WO}_{3}, *^{2}$ calculated value from mass loss $(\not)$ at $723 \mathrm{~K}, *^{3} 1: 1$ 
Table 3 Nitrogen contents and phases of decomposition products of monoclinic APT that was keeped at $703 \mathrm{~K}$ and $743 \mathrm{~K}$ for $5.4 \mathrm{ks}$ after ATB formed in various atmosphere.

(heating rate : $0.25 \mathrm{~K} / \mathrm{s}$, sample mass : $6000 \mathrm{mg}$ )

\begin{tabular}{|c|c|c|c|c|}
\hline & \multicolumn{2}{|c|}{$703 K$} & \multicolumn{2}{|c|}{$743 \mathrm{~K}$} \\
\hline & $\begin{array}{l}N \text { content } \\
(\$)\end{array}$ & $\begin{array}{l}X \text {-ray in- } \\
\text { tensity } \\
*\end{array}$ & $\mid \begin{array}{l}\mathrm{N} \text { content } \\
(\mathrm{S})\end{array}$ & $\begin{array}{l}X \text {-ray in- } \\
\text { tensity } \\
*\end{array}$ \\
\hline $0_{2}$ & 0.20 & $0 / 100$ & 0.18 & $0 / 100$ \\
\hline Air & 0.22 & $0 / 100$ & 0.18 & $0 / 100$ \\
\hline $\mathrm{N}_{2}$ & 0.62 & $100 / 0$ & 0.28 & $45 / 100$ \\
\hline $\mathrm{Ar}$ & 0.50 & $100 / 0$ & 0.18 & $0 / 100$ \\
\hline $\mathrm{H}_{2}$ & 0.79 & $100 / 0$ & 0.59 & $90 / 100$ 々 \\
\hline
\end{tabular}

* ATB $/ \mathrm{wO}_{3}$ (a.u.), tetragonal $\mathrm{WO}_{2.90}$

\section{した生成物を調べた。}

Table 3 に生成物の窒素量およびX線回折強度を示 す. 703Kにおける酸化雾囲気中で，A T B はアンモ 二アの解踓でゆっくりと重量減少しながら分解して単 斜晶 $\mathrm{WO}_{3}$ に変化する.

不活性男囲気中および僄元雾囲気ではA T B 単相て 存在し, 窒素量は還元雲囲気の水素中が最も多い。

$743 \mathrm{~K}$ においては，不活性雾囲気中でも A T B が分 解して単斜晶 $\mathrm{WO}_{3}$ に変化する。

水素中では A T B が還元されて正方晶W $\mathrm{O}_{2}$. 90 に 変化し,これに対応する反応熱は既察されなかった。

\section{$\mathbf{V}$ 桔 詥}

単斜晶および斜方晶 A P T の熱分解過程において生 成する酸化タングステンの粒度を支配する六方晶 $\mathrm{AT}$ Bの生成機棈を種々のA P T充塓量および雾囲気のも とで示差熱分析を行い,以下のことが明らかになった。 (1) A T B の生成量はA T B の生成が活発に起こる630 K近傍におけるアンモニアの残量に支配され，A P T充㙋量と票囲気に影響される。 A T B 単相 の生成に必要とされる空素量は $0.8 \%$ 以上である. (2)単斜晶 A P T の結晶水とアンモニアの解離はとも に吸熱反応であり, アンモニアの解離の吸熱量が 大きく $600 \mathrm{~K}$ で極大となる．A P T 充埧量の多い
場合，解離反応による吸熱量が大きく $700 \mathrm{~K}$ 近傍に おいてアンモニアの解離が迤れて A T B の生成に 必要な十分のアンモニアが残存し，生成物は $\mathrm{AT}$ B 単相となる. A T B は熱的な変化なしに無定 形AP T から生成する.

(3) A T B は還元性雲囲気, 不活性雲囲気, 酸化性雾 囲気の順に生成されやすく，逆の順序で分解され やすい，A T B は不活性雲囲気および酸化性塞囲 気の $760 \mathrm{~K}$ 近傍で発熱を伴ってWO 3 に分解する.

(4)単斜晶 A P Tにおいて, A P T充墳量の少ない場 合はアンモニアの解離による吸熱量が小さく, 解 離反応の進行が速く700K近傍で発熱を伴って無 定形A P Tから単斜晶WO 3 を生成する.

(5)斜方晶 A P Tにおいて, 結晶水とアンモニアの解 離は吸熱反底であり, 結晶水の解離の吸熱量が大 きいためアンモニアの解離が遅れて，A T B は単 斜晶A P Tより生成しやすい.

(6) アンモニアと公素の混合ガス中では A P T中のア ンモニアと塞囲気のアンモニアが平衡状態となっ て, A T B の生成はアンモニアの解離速度に影響 されない.

\section{文 献}

1)山本良治,郷谷清,志垣憲良:粉体および粉末冶金, 投稿中.

2)山本良治,松本明英,本川惺,志垣䨓良:粉体および粉 末治金,投稿中。

3)G.J.French and F.R.Sale:J.Mat.Sci., 16 (1981) 3427.

4)P.G.Dickens, A.C.Halliwell, D.J.Murphy and M.S.

Wittinghạ: Trans.Farad.Soc.,67 (1971) 794.

5)L. Bartha, G. Gyarmati , B.Kiss, T. Nemeth, A. Aalamon

\& T.Szalay:Acta.Chim.Sic.Hung., 101 (1979) 127.

6)L. Bartha, A.Kiss, J.Neugebauer and T.Nemeth:

High Temp.High Press., 14 (1982) 1.

7)Zou Zhigiang, Wu Enxi, Tan Aichun \& Qian Chungliang: 11th Plansee Seminar '85, Vol.1, RM42. Reutte,Austria, (1985) 337

8)J.W.van Put,T.W.Zegers and H.Liu:J.Refractory Metals and Hard Materials,10 (19991) 123. 